\title{
DAÑOS Y SAQUEOS DURANTE LA GUERRA DE LA TRIPLE ALIANZA. EI POBLADO DE BELLA VISTA ANTE LA OCUPACION PARAGUAYA DE 1865
}

\author{
Damages and pillages in the war of the Triple Allience. The Bella Vista villaje \\ under the Paraguayan occupation of 1865
}

\section{Dardo R. Ramírez Braschi}

\section{Resumen}

En los últimos meses de ocupación paraguaya a la provincia de Corrientes, en el marco de la guerra de la Triple Alianza (1865-1870), y durante su retirada, la actitud de los paraguayos hacia los correntinos fue diferente de cuando comenzó el conflicto.

En un inicio el ocupante intentó generar alguna atracción hacia los correntinos para que simpatizasen con su causa pero, con el transcurrir del tiempo y debido a las adversidades militares, el proceder se transformó violento y en ocasiones despiadado.

Si bien en todos los departamentos correntinos ocupados se produjeron daños y perjuicios a la población civil, en algunos fue más intenso que en otros. El caso del poblado de Bella Vista adquirió dimensiones extremas y en el presente artículo se estudia el origen, desarrollo y consecuencias de los actos de violencia que soportaron los pobladores de aquel Departamento.

Las principales fuentes utilizadas para este estudio provienen de los fondos documentales del Archivo Nacional de Asunción, el Archivo General de la Nación y el Archivo General de la Provincia de Corrientes.

$$
<\text { Corrientes }><\text { Paraguay }><\text { guerra }><\text { saqueos }>
$$

\begin{abstract}
During the last months of the Paraguayan occupation to the province of Corrientes, as part of the Triple Aliance war (1865-1870), the Paraguayans attitude towards the people from Corrientes changed. Initially the occupants tried to generate some attraction over the people from Corrientes in order to make them sympathize with their cause. Nevertheless, over time and due to military adversities, the procedure turned violent and sometimes merciless.

While all the peoples from the Departments of Corrientes suffered damages, some were more affected than others. The case of the town of Bella Vista acquired extreme dimensions. In this paper, we study the origin, development and consequences of the violence suffered by the people from that Department.
\end{abstract}

The main sources used in this study are the documentary collections of the National Archives of Asuncion, the General Archive of the Nation and the General Archive of the Province of Corrientes.

$$
<\text { Corrientes }><\text { Paraguay }><\text { war }><\text { pillage }>
$$


Ramírez Braschi. Bella Vista durante la ocupación paraguaya (1865).

“...se conoce que muy poca pena tienen por la desgraciada Corrientes, que han corrido y la despojaron limpio".

(Carta de Josefa Nibeyro a Wadislao Gramajo, Corrientes, 27 de Octubre de 1865, AGPC, Sala 7, Correspondencia Privada, legajo 5, 1865-1866)

El estudio de la guerra contra el Paraguay generó una fructífera producción historiográfica, la que se mantuvo en los últimos años. Nuevas tendencias e interpretaciones abordaron la cuestión, aportando reflexiones que se suman para comprender y explicar aquella guerra determinante para la construcción de los países que participaron. En la última década, los nuevos aportes como los de Francisco Doratioto y Thomas Whigham, desde la perspectiva político-militar; los estudios novedosos de Luc Capdevila sobre los impactos sociales y humanos de la contienda; y las reflexiones sobre las tendencias historiográficas aportadas por Liliana Brezzo, entre otros, dieron marco y dinamismo a nuevas interpretaciones.

El enfoque del impacto de la ocupación militar sobre la población civil en la guerra de la Triple Alianza ha sido anteriormente estudiada, sobre todo en la sociedad paraguaya, referente a saqueos, pérdidas inmobiliarias, consecuencia de pobreza, etc., pero no así se hizo sobre la población correntina. Además, las condiciones revestían situaciones distintas, ya que los saqueos en territorio correntino se dieron, casi en su totalidad, por un ejército vencido, decepcionado y en retirada, mientras que los saqueos en Asunción se produjeron por tropas que surcaban los caminos de la victoria.

El enfrentamiento de la alianza de Argentina, Brasil y Uruguay contra el Paraguay involucró fuertemente a las partes, pero los espacios geográficos donde se desarrollaron directamente las acciones bélicas alcanzaron un fuerte impacto, que repercutió sobre todo en la población civil de las ciudades, pueblos o villas, que no sólo sufrieron violencia militar, sino también las consecuencias de las victorias del vencedor y las derrotas del derrotado. Entre aquellas desventuras de la población civil, se encuentra el padecimiento por saqueos y destrucción de la propiedad privada.

En los meses que duró la ocupación paraguaya en la provincia de Corrientes, se registraron, en todos los departamentos correntinos ocupados, denuncias por saqueos con distintos grados de violencia. En este artículo se estudia uno de los casos más emblemáticos ocurrido en territorio argentino: el ataque al poblado correntino de Bella Vista. Si bien los daños y perjuicios, como consecuencia de la guerra, impactaron y generaron padecimiento a la sociedad civil correntina en todos los departamentos ocupados por las tropas paraguayas, estos tuvieron distintas intensidades.

\section{Situación política correntina}

La ubicación geográfica de la provincia de Corrientes hizo que se transformara en una pieza estratégica clave para todo el desarrollo de la guerra que libraron Argentina, Brasil y Uruguay, contra el Paraguay. Las relaciones conflictivas entre Argentina y 
Paraguay eran de larga data y se manifestaban clara y notoriamente en la política exterior de cada país, y estas actitudes se reflejaban en la prensa de la época. Los periódicos argentinos, tanto en Buenos Aires como en las provincias a partir del año 1864, hacían del tema de la relación con Paraguay y la política del jefe de Estado paraguayo Francisco Solano López, epicentro de críticas y hostigamientos. En la provincia de Corrientes, las opiniones se encolumnaron a través de dos periódicos con criterios enfrentados: "El Progreso" y "El Independiente". El primero de ellos, mitrista, y hostigador permanente hacia el Gobierno del Paraguay y el segundo, urquicista, y defensor de la política lopista. Estos periódicos no eran más que el reflejo de la opinión política de los grupos locales que, en el caso de Corrientes, estaban visiblemente diferenciados. Un sector se manifestó visiblemente al registrarse la ocupación paraguaya a Corrientes, ya que la sociedad correntina se dividió entre los que rechazaron la invasión y los denominados paraguayistas, que la apoyaron.

Numerosas familias se dividieron por esa causa, existiendo casos paradigmáticos al registrarse posiciones enfrentadas entre padres e hijos, tal el caso de Teodoro Gauna, paraguayista, y su hijo Federico Gauna, que combatió en los batallones argentinos; o la familia del coronel Basilio Báez, que comandó batallones correntinos y uno de sus hijos lo hizo desde las filas paraguayas. También podemos traer a la memoria el caso del gobernador Manuel Antonio Ferré y Nicolás Ferré, ambos, hermano y sobrino respectivamente del gobernador Pedro Ferré; o los casos de Pedro Rolón, hermano del gobernador José María Rolón, y Cayetano Virasoro, hermano del gobernador Benjamín Virasoro, entre otros. ${ }^{1}$

Desde el origen mismo de la invasión, y como consecuencia de esto, se iniciaron procesos por el delito de traición a la patria, siendo el primero contra Ramón Contreras durante los primeros días de mayo de $1865^{2}$; también el gobernador Lagraña acusó y presentó pruebas, ante el Fiscal General de la Provincia, denunciando a Tomás Bedoya, Cayetano Virasoro, José Luis Garrido, Antonio Díaz de Vivar, Domingo Igarzábal, Ulpiano Lotero, Roberto Billinghurst y José Luis Fernández, todos hombres miembros de familias socialmente conocidas y de constante participación pública. ${ }^{3}$ Es conveniente aclarar que ninguno fue condenado y todos fueron absueltos, y algunos de ellos, tal el caso del citado Contreras, llegaron a ocupar altos cargos en el Poder Judicial, mientras se desarrollaba aún la guerra contra el Paraguay. ${ }^{4}$ Un testimonio de Tiburcio Gómez Fonseca describe y simplifica esta situación a fines de noviembre de 1865:

"El Sr. Gobernador vino muy preparado contra los traidores, y expidió un decreto de destitución en masa. Pero no crea V. que ese mandato se ha cumplido. Los traidores que tienen

\footnotetext{
${ }^{1}$ Ramírez Braschi, Dardo. 2004. La guerra de la Triple Alianza a través de los periódicos correntinos 1865-1870. Corrientes, Moglia Ediciones, pp. 115 y 139.

${ }^{2}$ Archivo General de la Provincia de Corrientes, Copiador de Notas del Ministerio de Gobierno, Legajo 20, 1859-1869, F.129.

${ }^{3}$ AGPC, Copiador de Notas del Ministerio de Gobierno, Legajo 20, 1859-1869, F.131.

${ }^{4}$ AGPC, Copiador de Notas del Ministerio de Gobierno, Legajo 20, 1859-1869, Fs.161 y 186.
} 
Ramírez Braschi. Bella Vista durante la ocupación paraguaya (1865).

padrino no han salido, demás empleos. Y entre estos hay bien infames. Los demás siguen funcionando en sus puestos hasta $2^{\circ}$ orden, pues hasta hoy no se ha nombrado a nadie, para reemplazarlos. A excepción de un jefe de policía, para sustituir al que renunció. Los traidores de marca, pasean y se asocian a S. E. sin novedad, aunque dicen que los va a hacer fugar. Así van éstas y otras cosas, causando risa, a quien las observa con imparcialidad." 5

Del mismo modo se incentivaron denuncias públicas y privadas de parientes entre sí, como la realizada por Damaro Sánchez ante el gobernador Manuel I. Lagraña, que inculpó a su cuñado y su sobrino de ser paraguayistas. ${ }^{6}$ Una particular recomendación, dirigida por el ministerio de Gobierno al juez de paz de Paso de los Libres, exhorta a las autoridades locales a ser cautos y prudentes, en no proceder precipitadamente, ya que deben tener en cuenta las relaciones de amistad y parentesco que tenían los acusados del delito de traición a la patria. ${ }^{7}$ Las causas motivadoras que explican el accionar de los paraguayistas son diferentes, ya que algunos de ellos procedieron por convicción y otros por temor.

La Junta Gubernativa y los correntinos paraguayistas redoblaron esfuerzos por generar cierta independencia de las decisiones provenientes del Gobierno de Asunción $\mathrm{y}$, paralelamente, intentaron instalar la idea de un enfrentamiento con el Gobierno presidido por Bartolomé Mitre y su alianza con el Brasil, objetivo este último que no pudieron lograr. En aquel intento, impusieron algunas disposiciones que pretendían el manejo de su propia soberanía, como la que estableció que la bandera correntina sea la que flamee en los edificios públicos y la que deba portarse por los batallones provinciales, sosteniendo que "...este Estado ha conservado ilesa su soberanía, como lo demuestran los actos externos e internos del Gobierno, y como lo acredita aun, ante los mas profanos, el hecho de ser el pabellón correntino el que ha estado enarbolado en los edificios públicos del Estado, y principalmente en la casilla del Resguardo, como no pudo ocultarse a la escuadra brasilera."

Víctor Silvero, uno de los triunviros de la Junta Gubernativa, al constituir un batallón en el Departamento San Luis del Palmar, su primer acto fue entregar a la columna la "bandera correntina", afirmando que "ella simbolizaba la patria y su misión".9 Esta disposición se mantuvo hasta los últimos momentos de la ocupación paraguaya, como lo demuestra el caso de la batalla de Naranjitos, el 21 de septiembre de 1865, cuando el general Manuel Hornos capturó, entre los vencidos correntinos, sólo la bandera de

\footnotetext{
${ }^{5}$ AGPC, Sala 7, Correspondencia Privada, carta de Tiburcio G. Fonseca a Wadislao Gramajo, Corrientes 24 de Noviembre de 1865.

${ }^{6}$ AGPC, Correspondencia Oficial, Tomo 211, Fs.219.

${ }^{7}$ AGPC, Copiador de Notas del Ministerio de Gobierno, Libro de notas a jueces de paz, 1864-1866, Legajo 23, F. 201

${ }^{8}$ AGPC, Copiador de Notas de Ministerio de Gobierno, legajo 24, 1866-1869, F. 135.

${ }^{9}$ Archivo General de la Nación, Sala 7 10/5/12, Fs 110 y 110 vuelta.
} 
Corrientes, tal como lo describe en carta a Juan Vicente Pampín, cinco días después del combate. ${ }^{10}$ Además, la Junta Gubernativa de Corrientes dispuso, para la identificación de sus soldados, un uniforme distinto, que se diferenciase de los paraguayos y de las tropas aliadas. ${ }^{11}$ Las manifestaciones de esta naturaleza fueron constantes durante los meses que duró la Administración política de la Junta Gubernativa. ${ }^{12}$

\section{Avance paraguayo}

En la mañana del 13 de abril de 1865, cuando las tropas paraguayas toman los barcos argentinos "25 de Mayo" y "Gualeguay", se inicia formalmente la ocupación del territorio correntino y la preparación de los avances hacia los Departamentos del Sur provincial a través de la costa del río Paraná. Otra columna, incursiona por el territorio de las antiguas Misiones y tiene por referencia el río Uruguay, teniendo por objetivo atacar poblados costeros argentinos y brasileños. La columna del río Paraná estuvo, en un principio, al mando del general Wenceslao Robles, para luego pasar la jefatura al general Francisco Resquín. El grueso de la columna tuvo su campo de operaciones a la vera del río Paraná, con límite en las proximidades del río Santa Lucía, alcanzando influencia militar y política en Capital, Lomas, San Cosme, Itatí, Caá Catí, San Miguel, Empedrado, Mburucuyá, Saladas, San Roque, Bella Vista, Lavalle y Goya. ${ }^{13}$

\footnotetext{
${ }^{10}$ Ruiz Moreno, Isidoro J. 2008. Campañas militares argentinas. La politica y la guerra. Guerra exterior y luchas internas (1865-1874), Tomo IV, Buenos Aires, Ed. Claridad, p. 81.

${ }^{11}$ AGPC, Copiador Notas a Jueces de Paz, Legajo 23, 1864-1866. Circular del 15 de Julio de 1865.

${ }^{12}$ Para ver otros casos de manifestación política de la Junta Gubernativa consultar Dardo Ramírez Braschi, 2004. La guerra de la Triple Alianza a través de los periódicos correntinos 1865-1870. Corrientes, Moglia Ediciones, pp. 97 y 98.

${ }^{13}$ Respecto a la ocupación de Goya, el historiador Manuel F. Mantilla afirma que el Departamento fue ocupado parcialmente pero, de acuerdo a los registros del comerciante Tomás Mazzanti, se produjo una ocupación efectiva de la ciudad, no con la dimensión ocurrida en Bella Vista, pero de concreción efectiva. Ante la amenaza paraguaya, la mayoría de los goyanos emigraron a Esquina, quedando sólo los comerciantes extranjeros y los vecinos simpatizantes con los invasores. Las tropas paraguayas entraron el 3 de Julio a las 10:00 y se produjeron algunos saqueos, como el registrado en la casa de Julio Solari. Ante la presencia de los ocupantes, relata Mazzanti, algunas mujeres de la aristocracia local miraban con buenos ojos a la oficialidad paraguaya, diciendo: “iQué mozo simpático aquél!”. Por la tarde, los paraguayos se retiraron hacia Santa Lucía (ver Dardo Ramírez Braschi, "Registros y apuntes de Tomás Mazzanti sobre la guerra del Paraguay (1865)", Anales de la Junta de Historia de la Provincia de Corrientes, Moglia Ediciones, Corrientes, 2006).

Otro testigo de los acontecimientos sostuvo que los paraguayos entraron a Goya el 5 de Julio, permaneciendo un tiempo no mayor de cuatro horas, saqueando la casa de Julio Solano, impresor del periódico "La Esperanza", buscando las máquinas impresoras, las que no fueron halladas. Lo mismo hicieron con otras casas de comercio, pero las propiedades del testigo no fueron saqueadas (AGPC, Sala 7, Correspondencia Privada, carta de J. Altamirano a Wadislao Gramajo, Goya, 25 de Junio de 1865). Manuel Hornos, en un informe, sostiene que los paraguayos abandonaron la ciudad de Goya el 7 de Junio, después de haber saqueado las casas de negocios de los hermanos Baibiene y Julio Solano, tomando todos los paños que había en la plaza, por lo que giraron letras por su valor. Además tomaron prisionero al comerciante local Mariano Araujo (Archivo del general Mitre, Guerra del Paraguay, Tomo II Biblioteca La Nación, Buenos Aires, 1911, p. 171).
} 
Ramírez Braschi. Bella Vista durante la ocupación paraguaya (1865).

Entre las debilidades que se le atribuye a la Jefatura de guerra paraguaya está la ausencia, en el frente de batalla, de Francisco Solano López, quien se instaló en Humaitá, ${ }^{14}$ dejando en manos de sus generales la ejecución de operaciones de vanguardia, lo que produjo algunas desinteligencias y contradicciones, como el caso que llevó a la sustitución del general Robles por el general Resquín.

En este contexto adquieren importancia los combates de Riachuelo (11 de junio de 1865) y el de Paso de Cuevas (12 de agosto de 1865), especialmente este último por la cercanía al poblado de Bella Vista, que allana el camino para su saqueo. El combate del Paso de Cuevas se produce entre parte de la flota brasileña y un buque argentino, contra la artillería paraguaya apostada en las barrancas del Paraná. Los buques se dirigían aguas abajo rumbo al puerto de Goya. Una batería paraguaya ubicada en las barrancas de aquel paso, bombardeó a los buques, que traspasaron el ataque pero, a pesar de ello, tuvieron la pérdida de diez muertos y veinticinco heridos. Sólo un buque argentino formaba parte de la escuadra: el "Guardia Nacional", al mando del oficial Luis Py, quien se detuvo frente a la batería para retar -como si fuera un duelo- a los cañones paraguayos asentados en las barrancas. Esta postura del oficial argentino tuvo un costo alto ya que la estructura del buque fue seriamente dañada, dejando como saldo tres muertos y 12 heridos. Entre los muertos se cuenta un hijo del capitán Py y el guardiamarina José Ferré, hijo del gobernador de Corrientes, Pedro Ferré. Los brasileños reconocieron diecisiete muertos y treinta y cinco heridos. Si bien el combate duró casi todo el día, la flota aliada no sufrió la pérdida de ningún buque y los paraguayos mantuvieron intacta su artillería.

\section{Familias exiliadas en otros pueblos}

Por el avance de las tropas paraguayas hacia el sur y ante la amenaza evidente de la ocupación de Bella Vista, algunas familias huyeron del pueblo para refugiarse en otros puntos de la provincia o en las provincias de Entre Ríos, Santa Fe o Buenos Aires. La emigración se realizó hacia varios puntos hacia el Sur, en Goya ${ }^{15}$, Esquina ${ }^{16}$,

También en los alrededores de Goya, la población de los suburbios padeció los daños de los paraguayos (carta de Evaristo López a Manuel Ignacio Lagraña, del 10 de Junio de 1865, AGPC, C.O., T. 29, F. 141). La noticia de la derrota paraguaya en Uruguayana se festejó en Goya con cohetes de estruendos; a partir de allí los vecinos regresaron a la ciudad paulatinamente y para el mes de Noviembre de 1865 la mayoría estaba radicada nuevamente en sus hogares. Estas elevaron un pedido al Gobierno provincial para levantar un nuevo templo a la Virgen del Rosario, protectora de la ciudad. (AGPC, Correspondencia Oficial. Tomo 211. Fs. 94, - AGPC, Sala 7, Correspondencia Privada, carta de J. Altamirano a Wadislao Gramajo, Goya, 23 de Septiembre de 1865).

${ }^{14}$ Doratioto, Francisco. 2004. Maldita Guerra. Nueva historia de la guerra del Paraguay, Buenos Aires, Ed. Emecé, p. 138.

${ }^{15}$ Archivo General de la Provincia de Corrientes, Correspondencia Oficial, Tomo 210, Fs. 105 vuelta y Tomo 210, Fs. 175.

${ }^{16}$ AGPC, Correspondencia Oficial, Tomo 210, Fs. 178 
Mercedes ${ }^{17}$, Curuzú Cuatiá, Monte Caseros $^{18}$, Federación ${ }^{19}$, Rosario, Santa Fe, La Paz y Paraná $^{20}$, y el vapor "Esmeralda" trasladó a algunas de ellas a Buenos Aires. ${ }^{21}$

Pobladores desesperados huyeron a las islas del Paraná y otros se internaron en los bosques chaqueños. ${ }^{22}$ En agosto amarraron al puerto de Paraná tres buques completos con familias de Bella Vista y Goya. ${ }^{23}$ Para solventar los gastos que originaba la residencia de estas familias emigradas, se crearon comisiones de fomento de vecinos para ayudar en su subsistencia. En el Senado de la Nación, en la sesión del 26 de agosto de 1865, se discutieron sobre los fondos para solventar los gastos de ayuda a las familias emigradas, sosteniendo algunos legisladores que podían considerarse como gastos de guerra, mientras que otros solicitaron fijar una cifra máxima de egresos. ${ }^{24}$

Con la aprobación de la Ley, las comisiones fueron subvencionadas por el Gobierno argentino, y se giró inicialmente a la provincia de Corrientes, en Octubre de 1865 , la suma de 1.500 patacones para su funcionamiento. ${ }^{25}$ El gobernador Lagraña designó comisionados para que estuviesen al frente de la administración de esos fondos en distintas ciudades: en Goya, fueron nombrados el general José María Pinedo, el sargento mayor José C. Elordi, y José González; en Esquina, José Guastavino, Daniel Hayes y Lorenzo M. González; en Monte Caseros, Nemesio Corrales, Juan J. Ramos y Manuel Maurini. ${ }^{26}$ También el gobernador Lagraña invitó especialmente a José Jacinto Rolón a que participe desde la ciudad de Goya. ${ }^{27}$ Las familias emigraron con escasa ropa y nada de dinero, dejando todos sus bienes a merced del enemigo. Residir en otros poblados sin recursos hizo que no tuviesen dónde vivir, ni tener cómo vestirse ni alimentarse, salvo algunas personas que tuvieron la fortuna de ser albergadas en hogares, gracias a la solidaridad de los vecinos. De allí la importancia que tuvo el impulso de la conformación de aquellas Comisiones de ayuda a los emigrados por la guerra. El diario "Nación Argentina" se hizo eco de la situación y estado de las familias emigradas, noticia que alcanzó notoria difusión. ${ }^{28}$

\section{Ataque a Bella Vista}

\footnotetext{
${ }^{17}$ AGPC, Correspondencia Oficial, Tomo 210, Fs. 179

${ }^{18}$ AGPC, Correspondencia Oficial, Tomo 211, Fs. 50

${ }^{19}$ Archivo General Mitre, Tomo II, Biblioteca La Nación, Buenos Aires, 1911, p. 229.

${ }^{20}$ AGPC, Correspondencia Oficial, Tomo 210, Fs. 139

${ }^{21}$ AGPC, Correspondencia Oficial, Tomo 210, Fs. 129

${ }^{22}$ AGPC, Copiador de Notas del Ministerio de Gobierno, Legajo 24, Libro años 1866-1869, F. 144.

${ }^{23}$ Archivo del general Mitre, Tomo II, Biblioteca La Nación, Buenos Aires, 1911, p. 234.

${ }^{24}$ Congreso de la Nación Argentina, Diario de Sesiones de la Cámara de Senadores (1865), Buenos Aires, 1892, pp. 297- 300 .

${ }^{25}$ AGPC, Correspondencia Oficial, Tomo 210, Fs. 228

${ }^{26}$ AGPC, CNMG, Legajo 21, 1860-1869. Libro de Comunicaciones, F. 155.

${ }^{27}$ Correspondencia de Manuel Ignacio Lagraña a José Jacinto Rolón, Goya, 10 de Agosto de 1865. Diario Nación Argentina, Buenos Aires, 17 de Agosto de 1865.

${ }^{28}$ Diario Nación Argentina, Buenos Aires, 17 de Agosto de 1865.
} 
Ramírez Braschi. Bella Vista durante la ocupación paraguaya (1865).

Luego que la Jefatura militar del ejército paraguayo en operaciones sobre el río Paraná quedara al mando de Francisco Isidoro Resquín, sustituto de Wenceslao Robles, continúo la ocupación de territorios en el Sur provincial. El avance alcanzó las inmediaciones de Bella Vista, donde permaneció un mes ejecutando marchas y contramarchas. Las tropas de Resquín no hallaron resistencia militar ya que el general Paunero marchó, en el mes de julio de 1865, hacia el este, mientras que el general Nicanor Cáceres sólo operaba con algunas guerrillas.

Hasta la ocupación del poblado de Bella Vista, los pueblos correntinos habían sido -hasta cierto punto- respetados, pero, una vez ocupada esta villa, comenzaron los saqueos sistemáticos. ${ }^{29}$ En los primeros momentos de la ocupación, desde Abril a Junio de 1865, no se produjeron saqueos de consideración, ya que sólo se registraron algunos actos de pillaje aislados, debido a que era intención de la Jefatura militar paraguaya y de los correntinos paraguayistas generar una política de convencimiento y seducción a la población autóctona provincial. Hubo inicialmente algunos pillajes aislados, pero estos no fueron generalizados, lo que cambiará a partir de Julio de 1865. La Junta Gubernativa fue insistente con los jueces de paz para que sean severos con los delincuentes y se devuelvan los animales arrebatados a los vecinos perjudicados. ${ }^{30}$ Esta situación duró poco ya que, ante los primeros reveses militares, el padecimiento de los habitantes correntinos aumentó progresivamente, lo que derivó en una depredación generalizada.

El saqueo de Bella Vista, iniciado el 28 de julio de 1865, fue uno de los más crueles registrado en los poblados correntinos, tanto en propiedades privadas como públicas. Un vecino del lugar manifiesta: "El saqueo en Bella Vista es en general y bastante terrible, pero la casa Delfino está completamente destruida, a mi no me han dejado ropa ni colchón, todo me han llevado, y a este temor todos en general han sufrido". ${ }^{31}$ Algunos funcionarios lograron prevenirse ante la ocupación inmediata de la ciudad, como fue el caso del administrador de Rentas de las Aduanas Nacionales, quien pudo huir con la recaudación de veintisiete mil trescientos sesenta y cinco pesos. ${ }^{32} \mathrm{El}$ gobernador Manuel Ignacio Lagraña da a conocer los saqueos y daños en Bella Vista al vicepresidente de la República, haciendo referencia también de mujeres violadas. Esta es la única vez que se hace mención a violaciones de mujeres por tropas paraguayas. No se ha encontrado documentación que hablen de estos hechos; existe la posibilidad que tal vez no hayan ocurrido ya que, si fuese así, aquellos actos agresivos hacia las mujeres correntinas hubiesen sido denunciados reiteradamente y con precisión. Parece ser que la versión llegó a oídos de Lagraña cuando éste se hallaba en Goya, en los primeros días de agosto de $1865 .^{33}$

\footnotetext{
${ }^{29}$ Thompson, Jorge, 1910. La guerra del Paraguay, Tomo I. Buenos Aires. Talleres Gráficos de L. J. Roso y Cia., pp. 89 y 90.

${ }^{30}$ AGPC, CNMG, Legajo 23, Libro copiador de notas a jueces de Paz, 1864-1866, Fs. 183.

${ }^{31}$ AGPC, Correspondencia Oficial, Tomo 210, Fs. 71.

${ }^{32}$ AGPC, Correspondencia Oficial, Tomo 210, Fs. 101

${ }^{33}$ Archivo del Dr. Marcos Paz, Universidad Nacional de La Plata, Vol. 4, La Plata, 1963, p. 83.
} 
Los comercios fueron el primer objetivo de la tropas paraguayas, tal el caso de la casa de negocios de Félix Delfino, afincado en Bella Vista desde el año 1853, que fue saqueada y destruida, incluyendo dos depósitos de mercaderías, artículos que fueron embarcados en varios buques en distintos viajes que partieron para Asunción. ${ }^{34}$ De acuerdo a la información sumaria ante los Tribunales correntinos, testigos afirmaron que la acción la realizó una fuerza de 200 hombres aproximadamente, conducida por Germán Serrano, la que saqueó el poblado por varios días consecutivos, siendo más de cien carretas cargadas las que transportaron el botín al puerto, para depositarlo en los vapores de guerra "Yporá" y "Ugurey", como en varios barcos de vela. El despojo fue de tal magnitud que se llevaron puertas, cerraduras, marcos y horcones..$^{35}$ En un informe del Jefe político de Bella Vista, se cita que los paraguayos salieron de la ciudad con 17 carretas hasta Garzas, repitiendo la operación varias veces. ${ }^{36}$ Ante el avance paraguayo, entre los emigrados también estuvo Delfino, quien se instaló provisoriamente en Goya. ${ }^{37}$ Los daños contra los intereses de Delfino fueron casi totales, pero éste pudo recuperarse económicamente, ya que tres años después fue designado por el Gobierno de la provincia como proveedor general de las fuerzas comandadas por el coronel Raymundo J. Reguera. ${ }^{38}$

Respecto a comercios del poblado, los paraguayos buscaron información precisa de los depósitos y de las mercancías que tenían cada uno de los comerciantes, teniendo por objetivo el descubrir todo depósito oculto. Los comerciantes fueron llevados por los paraguayos e interrogados para que manifiesten el lugar y las mercancías que existían en el pueblo, para luego acercar los datos al general Resquín. ${ }^{39}$

También el saqueo en los establecimientos rurales y las estancias del Departamento fueron constantes; el más relevantes ha sido la incursión sobre uno de los establecimientos ganaderos más importantes de Bella Vista, como lo fue el perteneciente a Eugenia S. de Artaza. Sus estancias fueron saqueadas completamente, incluyendo construcciones y toda clase de ganados, alcanzando estos últimos diez mil cabezas de vacunos, trescientos setenta ovejas y cuatrocientos cincuenta equinos. ${ }^{40} \mathrm{El}$ saqueo en las zonas rurales fue realizado de manera generalizada, sin puntos selectivos. Los damnificados podían ser importantes estancieros o pequeños productores locales, con una o dos cabezas de ganado. ${ }^{41}$

En cercanías a Bella Vista, a seis leguas al sur del pueblo, sobre las barrancas del Paraná, se hallaba la estancia del inglés John Gannon, que residía hacía ya treinta años

\footnotetext{
${ }^{34}$ AGPC, Correspondencia Oficial, Tomo 211, Fojas 4 y 5.

${ }^{35}$ AGPC, Expedientes Judiciales, Legajo 15, Civiles, Capital, 1865.

${ }^{36}$ AGPC, Correspondencia Oficial, Tomo 210, F.71.

${ }^{37}$ AGPC, Sala 7, Correspondencia Privada, carta de E. Araujo a Wadislao Gramajo, a bordo del "Reinaldo", riacho de la Esquina, 3 de Agosto de 1865.

${ }^{38}$ AGPC, Copiador de Notas del Ministerio de Gobierno, Legajo 24, 1859-1869, F. 251.

${ }^{39}$ Archivo Nacional de Asunción, NE, 1696, interrogatorios a Pedro Morego, Pelegrín Denegri, Esteban Libieri y Cayetano Trabuco.

${ }^{40}$ AGPC, Sección Judiciales, Legajo 65.

${ }^{41}$ AGPC. Expedientes Administrativos. Reclamos deudas guerra del Paraguay. Libros I, II, III y IV.
} 
en la provincia de Corrientes. Los paraguayos, al incursionar por primera vez bajo el mando del general Robles, mostraron pasividad hacia él y sus bienes, recomendándole Robles que se mantenga neutral en la contienda. Pero, tiempo después, el 13 de agosto de 1865, se acercó al establecimiento una partida de soldados paraguayos que carnearon animales vacunos, llevándose además, maíz, mandioca y verduras. El día 20 se produce un violento ataque a la estancia de Gannon. A sablazos hirieron al propietario, dándolo por muerto, decapitando después a un muchacho de catorce años; seguidamente degollaron dos mujeres más, estando una de ellas embarazada, para retirarse con todo el botín que hallaron en la estancia, apropiándose de 1.000 cabezas de ganado, propiedad del inglés, y llevándose todos los caballos que encontraron. ${ }^{42}$

Las acciones fueron realizadas por las tropas invasoras que, en ocasiones, actuaron en complicidad con grupos locales, que tuvieron como cabecillas a referentes de la localidad, como lo fueron José F. Cáceres y Ramón Sangrá. Dada esta situación, el Jefe político Francisco Ferreyra manifestó, en carta al gobernador Lagraña, lo siguiente: "Una medida de urgente necesidad: la de nombrar una Comisión de personas idóneas que se ocupen, desde luego, del examen de la conducta de muchas personas que han sido el flagelo del pueblo; de los que han servido de guías a los invasores, de los que han acaudillado gavillas de ladrones; y de los que han sido desertores del ejército." 43

La propiedad del Estado también fue destruida y saqueada. Vecinos intentaron proteger algunos bienes públicos, como el caso de Dolores Molina, vecina del pueblo, quien ha entregado, a la Jefatura política, 35 sellos de a un real y 6 de diez pesos, pertenecientes al Erario provincial, diciendo que los referidos sellos fueron recogidos durante la ocupación. ${ }^{44} \mathrm{El}$ templo local también fue dañado y se apropiaron del hierro que estaba destinado a la nueva capilla ${ }^{45}$ e incluso sustrajeron la corona de plata y la vestimenta de la Imagen de la Virgen que la presidia. ${ }^{46}$ De acuerdo a la descripción del ingeniero británico Jorge Thompson -quien ejerció su profesión en el Paraguay al servicio de los jefes de Estado, Carlos Antonio López y Francisco Solano López-, muchas de las cosas robadas fueron enviadas a este último, como regalo, incluso un piano saqueado a Félix Delfino, que fue obsequiado a Elisa Lynch, primera dama en ese entonces del Gobierno paraguayo. ${ }^{47}$ El diario Nación Argentina referenció, en varias ocasiones, el estado del poblado de Bella Vista y el accionar paraguayo. ${ }^{48}$

\footnotetext{
${ }^{42}$ ANA, CRB, I-30, 24, 9.

${ }^{43}$ AGPC, Correspondencia Oficial, Tomo 211, Fs. 4 y 5.

${ }^{44}$ AGPC, Correspondencia Oficial, Tomo 211, Fs.171 vuelta.

${ }^{45}$ AGPC, Correspondencia Oficial, Tomo 211, Fojas 4 y 5.

${ }^{46}$ Whigham, Thomas. 2010. La guerra de la Triple Alianza, Causa e inicios del mayor conflicto bélico de America del Sur, Volumen I, Asunción, Ed. Taurus, p. 427.

${ }^{47}$ Thompson, Jorge. 1910. La guerra del Paraguay, Tomo I. Buenos Aires, Talleres Gráficos de L. J. Roso y Cia., p 90.

${ }^{48}$ Diario Nación Argentina, Buenos Aires, 18 de Agosto de 1865.
} 
Al producirse el retiro definitivo de los paraguayos de la ciudad, se llevaron todos los elementos que le eran posibles, destruyendo los que quedaban. ${ }^{49} \mathrm{El}$ desbande de ganado causó confusión entre los vecinos, ya que todos los animales fueron incautados. Pero sucedió que entre los vacunos dispersos, algunos de estos vecinos se apropiaron de animales sueltos que aparecían en sus campos y los marcaban para sí. En esta cuestión tuvo que intervenir el Juzgado de paz local. ${ }^{50}$ En otros casos, los animales fueran capturados por las autoridades locales y se procedió, desde el Gobierno, un mecanismo de devolución a los legítimos propietarios, los que debían probar sus pertenencias a través de las respectivas marcas de ganado. ${ }^{51}$ Luego de recuperada la ciudad por las tropas aliadas, prosiguió la inseguridad de la propiedad, ya que algunos oficiales argentinos tomaban ganado sin el procedimiento establecido para la compra e indemnización fijada por el Estado argentino, generando perjuicios entre los vecinos. Esto generó los reclamos reiterados del Jefe político de Bella Vista. ${ }^{52}$

El arreo del ganado por el ejército paraguayo pasó a ser sistemático en todos los departamentos de la provincia, procedimiento que se completaba paulatinamente cruzándolos a territorio paraguayo, lo que ocurrió hasta los últimos momentos de la ocupación. A fines de octubre y principios de noviembre de 1865 , el ejército comandado por el general Resquín cruzó -de regreso- el Paraná, arreando más de 100.000 cabezas de ganado vacuno saqueados de los campos correntinos. La mayoría de estos animales murió alrededor de los campos de Itapirú por falta de pasturas y otros miles murieron al no poder cruzar. ${ }^{53}$

Desde el inicio de la campaña militar paraguaya en territorio correntino se produjeron constantes arreos de animales y saqueos de propiedades con el fin de trasladarlo al Paraguay, como lo demuestran los reiterados testimonios y denuncias por daños. Tal el caso de Santos Insaurralde, que estuvo a cargo por unos meses del Juzgado de Paz de Caá Catí, y quien informó al gobernador Lagraña que:

"Los paraguayos que ocupan la Ciudad hacen de ésta muchísimos intereses. Saquean tiendas sin distinción, a Recalde no le han dejado nada, hasta los árboles le han cortado (...) Han llevado toda clase de hacienda tanto de vacunos como de caballos, en número de sesenta mil. Han saqueado todas las Estancias y poniéndoles fuego a algunas de éstas. En cualesquiera casa donde ellos entran roban

\footnotetext{
${ }^{49}$ AGPC, Correspondencia Oficial, Tomo 210. Fs. 248, Carta del Juez de Paz de Bella Vista al gobernador Manuel Ignacio Lagraña, del 11 de Octubre de 1865.

${ }^{50}$ AGPC, Correspondencia Oficial, Tomo 211, Fs.148.

${ }^{51}$ AGPC, Copiador de Notas de Ministerio de Gobierno, Libro de notas a jueces de paz, 1864-1866, Legajo 23, F. 216.

${ }^{52}$ AGPC, Correspondencia Oficial, Tomo 211, Fs.173

${ }^{53}$ Thompson, Jorge, 1910. La guerra del Paraguay, Tomo I. Buenos Aires, Talleres Gráficos de L. J. Roso y Cia., p 103.
} 
a manos francas, las patrullas mismas de noche roban a cualesquiera que encuentren, sin decir palabra". ${ }^{4}$

En sus Memorias, el coronel paraguayo Juan Crisóstomo Centurión registró que los soldados del general Robles cometieron algunos abusos sensibles, los que se debieron subsanar entregando vales contra la Nación a todos los perjudicados, y evitar así las exageradas reclamaciones que, después de la guerra, se formularon contra el Paraguay. ${ }^{55}$ También, oportunamente, la Junta Gubernativa dispuso que se aprovisionasen de telas u objetos necesarios para el vestuario destinados a batallones correntinos, por lo que se ordenó se tomen las mercaderías de los comercios de Bella Vista y Goya, a cuenta del Gobierno, emitiendo documentos que acrediten el crédito, para ser abonados por la Tesorería de la provincia. ${ }^{56}$ Los vales debían especificar las cantidades y clases de artículos incluyendo el precio corriente por mayor que tuviesen en plaza, debiendo ser firmados dichos recibos por el Jefe político de Bella Vista y dos vecinos honorables. ${ }^{57}$ Inicialmente estos documentos fueron emitidos y ninguno alcanzó a ser saldado por el Estado provincial, pero sí incorporados posteriormente por los damnificados a los reclamos como daños de guerra ocasionados por el enemigo. Por decreto del 14 de julio de 1865 la Junta Gubernativa también dispuso que sean considerados como artículos de guerra el ganado vacuno, los caballos y mulas, toda arma blanca y de fuego útil para la guerra, camisas y camisetas de algodón y lana, los ponchos de lana y algodón y los calzoncillos, paño de ponchos y estrella, bayoneta, cotín de algodón y lienzos, frenos de campos, gergas y monturas. ${ }^{58}$

Durante el repliegue en el mes de octubre de 1865, Francisco Solano López ordenó expresamente a Resquín que en la retirada llevasen toda clase de ganados y caballos que pudiera, pero con la obligación de emitir recibos y vales que generarían compromiso de pago por parte del Paraguay. ${ }^{59} \mathrm{~A}$ pesar de la orden y debido a la vorágine de los hechos bélicos, no se emitieron los bonos y ni siquiera se manifestó promesa de pago alguna; en cambio, sí, predominó la violencia y el saqueo.

\section{El registro de Augusto Luis Scotto}

A sesenta años de iniciarse la guerra contra el Paraguay, el periódico El Liberal, editado en la capital correntina, publicó un folletín histórico con el título "La invasión

\footnotetext{
${ }^{54}$ Archivo General de la Nación, Fondo Rufino de Elizalde, Legajo 8, doc. 670.

${ }^{55}$ Centurión, Juan Crisóstomo. 1976. Memorias o reminiscencias históricas sobre la guerra del Paraguay, Tomo I, Reedición, Asunción, Editorial Casa-Libro, p. 236.

${ }^{56}$ AGPC, CNMG, Legajo 21, 1860-1869. Libro de Comunicaciones, F. 153.

${ }^{57}$ AGPC, Copiador Notas del Ministerio de Gobierno, Legajo 17, 1857-1869. Comunicación de la Junta Gubernativa al Jefe político de Bella Vista, Corrientes, 18 de Agosto de 1865.

${ }^{58}$ Ocupación de Corrientes por fuerzas paraguayas. 1865. Documentos del Archivo provincial, Corrientes, Imprenta del Estado, 1929, p. 26.

${ }^{59}$ García Mellid, Atilio. 1964. Proceso a los falsificadores de la guerra del Paraguay, Tomo II, Buenos Aires, Ediciones Theoría, p. 325. Carta de Francisco Solano López a Resquín, Humaitá, 30 de Octubre de 1865 .
} 
paraguaya a Bella Vista", cuyo desarrollo abarcó los números de los días 20 al 26 de enero. Su autor, Augusto Luis Scotto, residente y súbdito de nacionalidad inglesa, testigo de aquellos hechos, describe la violencia, registrada en esos días, caracterizada por estar tan lejos de todos los principios del derecho internacional universalmente conocidos.

El autor anotó diariamente un registro de la ocupación paraguaya a Bella Vista, y a pedido de algunos vecinos del poblado y del Jefe político del lugar, Scotto se ocupó de escribir un relato de los robos y saqueos. Una de esas copias llega a manos del gobernador Manuel Ignacio Lagraña y por su intercesión fue publicado en los periódicos de Buenos Aires "La Tribuna" y "La Nación". El primero lo edita el viernes 27 de octubre de 1865 y, el segundo, un día después. El título que en borrador el autor dio al escrito fue: "Apuntes de los robos y saqueos cometidos por la vanguardia del ejército paraguayo compuesta de 6 a 7 mil hombres, al mando del mayor Avelino Cabral, de caballería, y el mayor José Eduviges Díaz, de Infantería, desde el día 28 de julio hasta el 6 de octubre, que se retiró el piquete paraguayo que estaba acampando en las orillas del pueblo de Bella Vista".

El autor compara los daños sufridos en Bella Vista con respecto a la Capital de la provincia, afirmando que:

"En la propia capital de la provincia no se cometió incendios
y depredaciones semejantes. Se procedió como si existiera
el deliberado propósito de destruir totalmente un pueblo
que hace apenas diez años era un simple agrupamiento de
ranchos y hoy estaba en pleno desarrollo hasta a llegar a
superar en muchos aspectos a la vieja capital. Había en Bella
Vista, grandes casas de comercio, importantes tanto por su
surtido como por su crédito y giro comercial, no existiendo
ni en la misma ciudad de Corrientes establecimientos de esa
importancia ni siquiera iguales". ${ }^{0}$

Al referirse Scotto a la decisión de Francisco Solano López de ocupar territorio correntino, da un lugar de importancia a la interpretación del supuesto o real apoyo que le debería haber brindado Justo José de Urquiza. ${ }^{61}$ Según afirmaciones de Manuel F. Mantilla, miembros del partido federal se plegaron a los paraguayos ${ }^{62}$, cuestión que hemos estudiado detalladamente en otra oportunidad. ${ }^{63}$ Esta asociación de un sector político con los paraguayos manifiesta y pone a luz las cuestiones pendientes

\footnotetext{
${ }^{60}$ AGPC, Hemeroteca, Caja 305, Periódico “El Liberal”, Corrientes, 20 de Enero de 1925.

${ }^{61}$ AGPC, Hemeroteca, Caja 305, Periódico "El Liberal”, Corrientes, 20 de Enero de 1925.

${ }^{62}$ Mantilla, Manuel Florencio. 1972. Crónica Histórica de la Provincia de Corrientes, Tomo II, Buenos Aires, p. 271.

${ }^{63}$ Ramírez Braschi, Dardo. 2004. La guerra de la Triple Alianza a través de los periódicos correntinos 1865-1870, Corrientes, Moglia Ediciones, pp. 101 a 139.
} 
Ramírez Braschi. Bella Vista durante la ocupación paraguaya (1865).

e inconclusas en la política argentina después de la batalla de Pavón y la consecuente hegemonía de Buenos Aires sobre el Interior.

El 28 de julio, a últimas horas de la tarde, el Jefe político Francisco Ferreyra reunió a los residentes extranjeros para informar la inminente llegada del ejército paraguayo, y propuso abandonar el poblado debido a que no se podía hacer frente a tamaña fuerza militar. Las familias huían por todos los medios, dirigiéndose a distintos puntos al sur o cruzando el río Paraná hacia territorio chaqueño con las pocas canoas que había. El cura local Agustín de los Santos y algunos comerciantes extranjeros, entre los que estaban Francisco Carrega, Juan Villanueva, Esteban Sussoni, Telmo Costa, Sebastián Forques, entre otros, fueron llevados al campamento paraguayo, siendo detenidos para luego permanecer en cepos e incomunicados.

El español Policarpo de Artaza también fue llevado prisionero y sometido a interrogatorios con la finalidad de que aporte datos sobre el ejército argentino, los batallones de vanguardia y su relación con personas de otras ciudades. Luego de ser llevado ante el general Resquín fue autorizado, junto al comerciante Guetta y Scotto, a regresar a Bella Vista, pudiendo escapar una noche con una canoa río abajo hacia Goya, para luego ir a Buenos Aires, donde describe y publica su experiencia vinculada a la ocupación paraguaya a Bella Vista. Estos datos fueron volcados por el mismo Artaza en un registro publicado en un diario porteño con el título de "Atrocidades de los paraguayos", donde manifiesta también la valentía de los soldados del país invasor, como la carencia de táctica militar. En su informe hace mención del empeño constante por parte de los ocupantes de inculcar y recordar la idea de que Buenos Aires, con su proceder, se engrandecía a costa de las demás provincias. ${ }^{64}$

La vida de los súbditos italianos y sus familias fue garantizada por la intervención de la tripulación del buque de la marina real italiana "Príncipe Oddone", que arribó al puerto de Bella Vista el 8 de agosto. También fue saqueada la casa del italiano Bernabín Cotta, Andrés Cotta y Cayetano Trabuco ${ }^{65}$ Simultáneamente a aquéllas acciones, grupos armados paraguayos retiraban de almacenes, tiendas y casas particulares de vecinos todo tipo de alimento y proveeduría, la que en su mayor parte fue embarcada hasta Humaitá. ${ }^{66}$ En la noche del día 8, ingresaron las primeras tropas de vanguardia de los batallones correntinos al mando del subteniente de caballería Pedro María Acosta, el que tomó posesión provisoria del pueblo. ${ }^{67}$

El registro escrito de Scotto es una de las fuentes más importantes para el análisis de aquellos casi diez días de padecimiento del poblado de Bella Vista que sucumbió en una larga y oscura noche de incertidumbre y terror, tanto para argentinos como extranjeros.

\footnotetext{
${ }^{64}$ Diario "La Tribuna" de Buenos Aires del 27 de Octubre de 1865 y reproducido por el diario "Nación Argentina" el 4 de noviembre del mismo año.

${ }^{65}$ AGPC, Hemeroteca, Caja 305, Periódico "El Liberal", Corrientes, 26 de Enero de 1925.

${ }^{66}$ AGPC, Hemeroteca, Caja 305, Periódico "El Liberal", Corrientes, 20 de Enero de 1925.

${ }^{67}$ AGPC, Hemeroteca, Caja 305, Periódico "El Liberal", Corrientes, 26 de Enero de 1925.
} 


\section{¿Por qué los saqueos adquirieron tamaña magnitud?}

Aproximarnos a encontrar respuesta a este interrogante no es tarea sencilla. Las denuncias de saqueos reiterados y de importantes dimensiones comenzaron a efectuarse después de la toma provisoria de Corrientes por el ejército Aliado el 25 de mayo de 1865, adquiriendo mayor intensidad después de la batalla del Riachuelo (11 de Junio). Los reveses y la no concreción de objetivos militares por parte del Paraguay y la expectativa no cumplida de adhesión masiva de correntinos a la causa paraguaya, hizo que cambiasen las estrategias y, sobre todas las cosas, la reacción y el proceder de las tropas lopistas. Durante el primer período de ocupación del territorio correntino, se buscó seducir a la población hacia la causa paraguaya, por lo que inicialmente los ocupantes se esforzaron por ser prudentes en las acciones contra los habitantes y sus propiedades.

Posteriormente las adversidades llevaron a las tropas paraguayas a tomar otra actitud, que alcanzaba, en ocasiones, extremos de crueldad. Con el transcurrir de los días, especialmente a partir de la segunda quincena del mes de junio, se multiplicaron los ataques y saqueos a la población civil y sus propiedades, cautiverios de mujeres y prisión para los hombres. ${ }^{68}$ Los ataques, en este sentido, en el mes de julio alcanzaron proporciones no previstas en un principio por la Jefatura militar paraguaya.

Cuando se preveía la posible colaboración o neutralidad de Justo José de Urquiza, ésta fue descartada, y cuando no se alcanzó la adhesión de departamentos de la Provincia que se sumaran a la causa paraguaya, se gestó una reacción violenta contra todos aquéllos que en un principio no fueron considerados enemigos directos. Si bien grupos de correntinos adhirieron directamente a la causa del Paraguay, estos no tuvieron la dimensión que esperaba el presidente López, tal como lo manifiesta en una comunicación a la Junta Gubernativa de Junio de 1865. Las expectativas de los paraguayos estaban en que los correntinos otorgasen mayor colaboración y garantías, y al no materializarse como López pretendía, éste llegó a manifestar:

\footnotetext{
${ }^{68}$ El caso de las mujeres correntinas que fueron llevadas cautivas al Paraguay adquirió una dimensión extraordinaria en el imaginario popular de la guerra contra contra esta país. Estas mujeres, algunas de ellas esposas de jefes militares argentinos vinculados con el mitrismo, fueron arrebatadas de sus hogares en la tercera semana del mes de Julio, aproximadamente tres meses después de la ocupación paraguaya a Corrientes. Hay que puntualizar que además de las cinco mujeres, conocidas y recordadas por la historiografía local, existieron otras, y el diario "Nación Argentina" en su edición del 2 de Agosto de 1865 afirma que el 12 de Julio "veinticuatro" mujeres, todas oriundas de la provincia de Corrientes fueron cautivas y llevadas a territorio paraguayo. Por nuestra parte localizamos a otras que reclamaron su padecimiento y solicitaron indemnización de daños por su cautiverio, como el caso de Carmen Ruiz Moreno de Cobiello (Expediente $N^{\circ} 853$ de reclamos sobre perjuicios por la ocupación paraguaya a la Provincia de Corrientes). Se esbozaron diversas explicaciones del proceder de los paraguayos, pero es interesante dar a conocer la versión dada por Víctor Silvero en la causa penal en la que fue imputado por el delito de traición a la patria, donde declaró que la reacción paraguaya se fundamentó en la incautación de comunicaciones que estas mujeres mantenían girando información a sus familiares en la vanguardia argentina. (Archivo General de la Nación, Sala 7 10/5/12).
} 
Ramírez Braschi. Bella Vista durante la ocupación paraguaya (1865).

"La continuación de este estado de cosas pondrá al Paraguay en la dura necesidad en obsequio del feliz éxito de la lucha y de la seguridad de las operaciones de sus ejércitos, de no contemplar ya al Estado de Corrientes y la Junta Gubernativa como aliado y amigo, sino como una población enemiga y peligrosa, adaptando su política a ésta, una convicción que tanto repugna a sus sentimientos". ${ }^{69}$

Los meses demostraron que el trato de amigo hacia los correntinos se desfiguró, convirtiéndose en peligroso rencor, fruto de la impotencia.

Sin la alianza con Urquiza ni la masiva colaboración esperada de correntinos, los planes de Francisco Solano López cambiaron y, a la vez, se diluyeron. Como consecuencia de esto, gran parte de la reacción final contra la población civil y sus propiedades se debió a un sentimiento de impotencia ante el fracaso de la campaña del ejército paraguayo en territorio correntino, y el antiguo amigo y aliado pasó a ser también parte del enemigo.

\section{Reclamos por daños y perjuicios}

Los reclamos de indemnizaciones por daños y perjuicios tienen antecedentes en la historia política correntina. No abundaremos en detalle, pero citaremos, por ejemplo, entre los reclamos particulares anteriores a la invasión paraguaya, la demanda iniciada por Juan Madariaga contra el Gobierno de Benjamín Virasoro varios años después de la caída política de este último ${ }^{70}$; y numerosos reclamos posteriores que se proyectaron en la década de 1860 y 1870. Con aquellos fines también se constituyó la Comisión Clasificadora de la Deuda por indemnización de la Nación a la Provincia de Corrientes, por suministros a los Ejércitos Libertadores, de acuerdo a la ley nacional del 13 de noviembre de $1863,{ }^{71} \mathrm{y}$ las numerosas informaciones sumarias para reclamos por daños iniciadas por los damnificados de las luchas civiles correntinas en la década de $1870 .{ }^{72}$

\footnotetext{
${ }^{69} \mathrm{ANA}, \mathrm{CRB}, \mathrm{I} .30,22,45$.

${ }^{70}$ AGPC, Sección Judiciales, Legajo 34, año 1871.

${ }^{71}$ AGPC, Expedientes Administrativos, Legajo 144, año 1866.

${ }^{72}$ Algunos expedientes por reclamos de enfrentamientos políticos correntinos se iniciaron a consecuencia de los conflictos de los años 1871 y 1878, como por ejemplo: Año 1872, B. de Gómez, Fortunata, denunciando información para justificar los perjuicios que le han causado las fuerzas del coronel Reguera - Año 1872, Ortiz, Nepomuceno, produciendo información sumaria para justificar auxilios forzosos (AGPC, Sección Judiciales, Tomo 38) - Año 1872, Alamán, Juan A., sobre daños y perjuicios sufridos por el ejercito de la Revolución (AGPC, Sección Judiciales, Tomo 39) - Año 1873, Alamán Juan A., sobre información sumaria de D. Alamán y D. Carmelo Alegre para acreditar los perjuicios sufridos por las fuerzas revolucionarias (AGPC, Sección Judiciales, Tomo 43) - Año 1873, Escalante, Eleuterio sobre información sumaria para justificar los auxilios entregados a las fuerzas del coronel Reguera (AGPC, Sección Judiciales, Tomo 44) - Los reclamos por la revolución del año 1878 son los siguientes: Año 1878, Barrios, Vicente; Año 1878, Garrido, Fortunato, por su madre D. Benigna Alegre de Garrido; Año 1878, Moreno, Eugenio, en representación de D. Bonifacio Benítez, (AGPC, Sección Judiciales, Tomo 70) - Año 1881, Alvarez Sánchez Negrete, Juana, representada por D. Martín Miranda
} 
Por iniciativa del gobierno argentino, y en cumplimiento de los acuerdos de paz, se abrió en 1877 un registro de reclamos de vecinos que sufrieron daños y perjuicios por la ocupación paraguaya en la provincia. Si bien el departamento Bella Vista no fue el que presentó el mayor número de damnificados, sus reclamos estuvieron entre los más elevados y costosos, alcanzando los 316 expedientes.

Los reclamos por daños y perjuicios se realizaron siguiendo los procedimientos y exigencias que tuvieron como fundamento la firma del tratado de paz con el Paraguay del 8 de febrero de 1876, por lo que el Estado vencido debió pagar a la República Argentina los gastos que ocasionó durante la guerra, los daños a propiedades públicas y perjuicios causados a personas y propiedades particulares. La materialización de esos pagos no se concretó, ya que sólo se entregaron bonos que nunca fueron efectivizados en dinero. ${ }^{73}$ Los distintos reclamos por daños de guerra tuvieron diferente origen y motivos, no sólo de carácter público y privado, sino también a los daños a los proveedores del ejército de operaciones. ${ }^{74}$ Pero, tempranamente, la provincia impulsó una vía de reclamos y al poco tiempo de finalizada la ocupación paraguaya del territorio correntino, el gobierno fomentó la creación de comisiones en los distintos departamentos para que recolectaran toda denuncia, datos e información de los daños a particulares por las tropas del ejército paraguayo. Dichas comisiones estuvieron compuestas por dos o tres ciudadanos respetables del vecindario, con la presidencia

- Año 1881, Ferreyra, Clemente, por D. Bernabé Zárate; Ferreyra, Clemente, en representación de D. Ciriaco Rajoy - Año 1881, López, Casiano, Moreno, Rafael, solicita en representación de D. Sebastián Fernández - Año 1881, Ojeda de Escalante, María C. - Año 1881, Romero, Conrado, en representación de Pedro Miño (AGPC, Sección Judiciales, Tomo 81) - Año 1881, Giménez, Tomás, (AGPC, Sección Judiciales, Tomo 82) - Año 1881, Chaine, Esteban, por D. Justo G. de la Fuente - Año 1881, Esquivel Isidro - Año 1881, Ferreyra, Clemente por D. Nicolás Monzón - Año 1881, Maidana, Manuel - Año 1881, Marcenaro, Fortunato en representación de D. Antonio Gavini - Parsi, Pablo, por D. Exequiel Correa - Año 1881, Rojas, Guillermo, en representación de D. Bernardo Roselli (AGPC, Sección Judiciales, Tomo 83) - Año 1881, Aquino, Claudio (AGPC, Sección Judiciales, Tomo 84) - Año 1881, Chaine, Esteban, por D. Cipriana B. de Cajita - Año 1881, Galarza, Roque - Moreno Rafael en representación de D. Pedro Altamirano - Año 1881, Moreno, Eugenio en representación de D. Tomasa Aguilar de Canteros (AGPC, Sección Judiciales, Tomo 85) - Año 1881, Ayala de Oviedo, Rufina, representada por D. Francisco Antonio Lezcano - Chaine, Esteban por D. Juana T. Gutiérrez - Año 1881, Incidente seguido entre el Ministerio Fiscal y D. Emilio Gallino en representación de D. Pascual Bertivolli, sobre reclamos de perjuicios sufridos con motivo de la revolución de 1878 - Año 1881, López, Brígida - Año 1881, Maidana, Liborio - Año 1881, Información sumaria instruida por daños y perjuicios sufridos en sus intereses por D. Simeón Paiba durante la revolución de 1878 - Año 1881, Ríos, Manuela - Año 1881, Rojas, Lorenzo, M. - Año 1881, Romero, Conrado - Año 1881, Romero, Eleuterio (AGPC, Sección Judiciales, Tomo 86).

${ }^{73}$ Brezzo, Liliana M. - Figallo, Beatriz. 1999, La Argentina y el Paraguay, de la guerra a la integración, Rosario, Instituto de Historia. Facultad de Derecho y Ciencias Sociales del Rosario, Pontificia Universidad Católica Argentina, pp. 35-48.

${ }^{74}$ Ramírez Braschi, Dardo. 2012. "Reclamo de deudas al Estado argentino por provisiones en territorio correntino durante la guerra contra el Paraguay". En: Cuarto Encuentro Internacional de Historia sobre las operaciones bélicas durante la guerra de la Triple Alianza. Instituto de Cultura de la Provincia de Corrientes; Asociación Cultural Mandu ara (Paraguay) y Instituto de Investigaciones Históricas y Culturales de Corrientes, Noviembre 8-9, 2012; Corrientes, Argentina (en prensa). 
Ramírez Braschi. Bella Vista durante la ocupación paraguaya (1865).

del juez de paz del lugar. Era preocupación del gobierno recabar todos los datos de la manera más fidedigna posible y que no dejen dudas de su legitimidad. La formalidad del expediente consistía en una información sumaria, donde se recibía el reclamo del damnificado con la relación de los hechos como ocurrieron, presentando testigos como pruebas de los dichos. Las autoridades quisieron agilizar este trámite, por lo que se incentivó a que fuese fácil, legal y de poco costo. ${ }^{75}$

En Bella Vista se registró el reclamo de un proveedor del ejército argentino que perdió parte de su fortuna en aquella ocupación, tal es el caso de Telésforo A. Díaz. Debido a la urgencia en la provista al ejército argentino, bajo las órdenes de Wenceslao Paunero, Díaz no pudo firmar contrato formal con el Estado nacional, pero sí logró un acuerdo aprobado por Juan Gelly y Obes, el 20 de abril de 1865. La provista debía ser de carne y vicios (yerba y tabaco), y no se pudo fijar el precio de la carne -al por mayor- que se comercializaba en Entre Ríos y Corrientes, por no tener un precio base de referencia. Telésforo Díaz acompañó al general Paunero en su desembarco en Bella Vista, y supervisó la entrega de provista correspondiente. Es de observar en sus informes, que el ejército correntino llevaba adelante la acción bélica, en el primer mes de lucha, en la más extrema pobreza, sin contar con provisión alguna. Debido a ello, aquellas mercaderías estaban destinadas a evitar la miseria y la deserción de los batallones correntinos. ${ }^{76}$

Díaz desembarcó la proveeduría en Bella Vista, pero el avance de las tropas paraguayas en esa ciudad produce que las filas, proporcionalmente muy menores de la vanguardia del ejército argentino, retrocediesen para garantizar seguridad, por lo que el cargamento fue tomado por los paraguayos sin resistencia. Los reclamos ante el Estado se sustentaban en que Díaz recibió órdenes de dejar las mercaderías en Bella Vista, a pesar que éstas fueron hechas verbalmente y no por escrito. Pero la entrega efectiva no se realizó, debido a que el general Hornos, en cercanías de Bella Vista, no aceptó la provista, alegando que la misma debía hacerla otro proveedor que había acordado con Bartolomé Mitre. Al no entregarse estas provistas, quedaron en Bella Vista, y se apropiaron los paraguayos de las ocho carretas de mercaderías, durante su incursión destructiva de la ciudad. Estos reclamos se sucedieron a partir de los años 1868-1869, y no fueron efectivizados por el Estado, alegando su falta de responsabilidad por las pérdidas. $^{77}$

Los cientos de reclamos se hicieron por vía del Estado nacional en cumplimiento a los tratados firmados con el Paraguay, pero existe un caso en particular que tuvo otra vía jurisdiccional, cual fue el reclamo del Jefe político de Bella Vista, Francisco Ferreyra, quien inicia acciones judiciales contra José Francisco Cáceres, por indemnización de los

\footnotetext{
${ }^{75}$ AGPC, Copiador de Notas del Ministerio de Gobierno, Libro de notas a jueces de paz, 1864-1866, Legajo 23, Fs. 216 y 227.

${ }^{76}$ Exposición que hace a los miembros del Congreso el ciudadano Telésforo A. Díaz, en su reclamación al Gobierno argentino por la pérdida de dos cargamentos de artículos destinados al ejército correntino, al inicio de la guerra del Paraguay, en el año 1865. 1878. Buenos Aires. Imprenta de Pablo E. Coni, p. 5.

${ }^{77}$ Ibid. pp. 11-16.
} 
daños ocasionados. Cáceres era oriundo de Corrientes que adoptó la causa paraguaya y mantuvo, durante la permanencia de las tropas invasoras en Bella Vista, relaciones muy cercanas con las mismas. Ferreyra reclama los perjuicios, no al Estado beligerante, sino a una persona física que participó en el conflicto. ${ }^{78} \mathrm{La}$ demanda fue asentada ante el Juzgado de Primera Instancia en lo Civil de la Capital, a cargo del juez Lisandro Segovia, y fue presentada el 18 de mayo de 1866 donde el reclamante manifestaba que el día 17 de mayo de 1865, el establecimiento de estancia denominado "Laguna Barrios", situada en el departamento Bella Vista, distrito de Isla Alta, fue incendiada y saqueada por José Francisco Cáceres, que respondía al mando militar paraguayo. Entablada la acción judicial, con el patrocinio de Gabriel Esquer, se pasa vista a Damasceno Fernández, Defensor de Ausentes, quien alega la necesidad de rechazar el planteo, fundándose en que Cáceres respondía órdenes de los mandos militares paraguayos, y que al ser argentino y cometer, por ende, el delito de traición a la patria, no sería jurisdicción de los tribunales civiles en los que debe plantearse la cuestión, y que si se registrase responsabilidad en los daños de guerra, ésta debe ser respondida por las naciones beligerantes. La parte actora argumentó sus pruebas en seis testimoniales, las que describieron los hechos, donde la mayoría aseveró haber escuchado, por parte de los atacantes, gritos de ¡Vivas al Paraguay!, ¡Vivas al general Robles! y ¡Muera Ferreyra! Pero el defensor de ausentes puso en duda estas testimoniales, y las cuestionó por inverosímiles, preguntándose qué hacían estos testigos, tan cerca de los batallones paraguayos, como para conocer con detalles precisos lo ocurrido. Dejaba entender que si es así, los testigos formaban parte de aquella columna.

La sentencia, en primera instancia, condenó el proceder de Cáceres, y la Cámara de Apelaciones dictaminó en el mismo sentido, dictándose embargo sobre las pertenencias que éste poseía en el departamento Mercedes, donde se domiciliaba. ${ }^{79}$

Este es un caso particular al que se dio lugar a la responsabilidad civil de una persona física que ocasionó daños en circunstancias de guerra. Si bien en otras ocasiones existieron procesos en el fuero penal por el delito de traición a la patria, todos los imputados fueron sobreseídos. Este es un caso extraordinario, en que la Justicia correntina hace lugar a una demanda civil por daños y perjuicios contra una persona física y no contra el Estado beligerante. Hay que recordar que Ferreyra, durante la ocupación de Bella Vista, ocupó el cargo de jefe político, por lo que era una persona conocida y de trascendente participación política y pública, representante del gobierno en el pueblo. Tal vez allí radique el ensañamiento con que ocurrieron los hechos en el establecimiento rural destruido.

\section{Algunas acciones judiciales contra paraguayistas}

Inmediatamente después del retiro de las tropas paraguayas y que el gobierno de Manuel Ignacio Lagraña se hiciese cargo de la administración de toda la jurisdicción

\footnotetext{
${ }^{78}$ AGPC, Expedientes Judiciales, Legajo 18, Civiles, Capital, Año 1867.

${ }^{79}$ AGPC, Expedientes Judiciales, ídem.
} 
Ramírez Braschi. Bella Vista durante la ocupación paraguaya (1865).

provincial, comenzaron los mecanismos para iniciar los procesos por el delito de traición a la patria a todos aquellos correntinos que colaboraron con el invasor, comúnmente conocidos como paraguayistas. Estos procesos no fueron numerosos teniendo en cuenta el porcentaje de la población local que colaboró directa o indirectamente con la Junta Gubernativa y las tropas paraguayas. Todos los procesos tuvieron el mismo final: los imputados no fueron condenados, sino absueltos de toda responsabilidad. ${ }^{80}$ Pero el caso más paradigmático ha sido el promovido contra el integrante de la Junta Gubernativa, Víctor Silvero, quien fue juzgado por la Corte Suprema de Justicia de la Nación, a partir de 1874, siendo también el fallo absolutorio. ${ }^{81}$

También se efectuaron algunas causas criminales por hechos acontecidos relacionados con la guerra, tal es la iniciada de oficio en el Juzgado del Crimen de Capital contra Juan Bautista Podestá, por homicidio e incendio de una casa de familia cuando la ocupación paraguaya a Bella Vista. ${ }^{82}$

En Bella Vista se va a producir un procedimiento más, esta vez relacionado al embargo de bienes contra quien colaboró con los paraguayos, tal es el caso de Sinforoso Cáceres, otro de los triunviros de la Junta Gubernativa que gobernó durante la ocupación. ${ }^{83}$ Este caso no es de naturaleza judicial, sino estrictamente política, ya que la orden emanó del Gobierno de la provincia, embargando todos los bienes de Cáceres, incluyendo su establecimiento rural "Las Palmitas" y más de 3.000 animales, entre los cuales había 2.289 vacunos. ${ }^{84}$ La medida punitiva no fue por orden judicial sino por decreto del gobernador Lagraña, del 31 de octubre de 1865, ordenando la medida y autorizando al Jefe político de Bella Vista a vender dichos bienes en pública subasta. ${ }^{85}$ Este procedimiento político administrativo se aproximaba más a una confiscación de bienes que a un procedimiento de embargo ordenado por las vías correspondientes a derecho. ${ }^{86}$ A raíz de aquella medida, los hijos de Cáceres (aún menores de edad) cayeron en una situación de miseria económica, al extremo de quedar incluso con dificultades

${ }^{80}$ Ramírez Braschi, Dardo. 2004. La guerra de la Triple Alianza a través de los periódicos correntinos 1865-1870, Corrientes, Moglia Ediciones, pp. 101 a 139.

${ }^{81}$ Ramírez Braschi, Dardo. "Análisis del Expediente judicial por el delito de traición a la patria contra Víctor Silvero, Miembro de la Junta Gubernativa correntina en 1865". En: XX Congreso de Historia Argentina y Regional. Academia Nacional de la Historia, agosto 21-23, 2003; La Plata, Argentina.

${ }^{82}$ AGPC, Expedientes administrativos, Leg. 144, Enero-Diciembre 1866.

${ }^{83}$ Ramírez Braschi, Dardo. 2004. La guerra de la Triple Alianza a través de los periódicos correntinos 1865-1870, Corrientes, Moglia Ediciones, pp. 123 a 125.

${ }^{84}$ AGPC, Expedientes Administrativos, Legajo 145, Enero-Diciembre 1866.

${ }^{85}$ ROPC, Años 1865-1866, Imprenta de "La Verdad", Corrientes, 1877, p. 56.

${ }^{86}$ Además de las confiscaciones a los bienes de Sinforoso Cáceres, se procedió -de la misma maneracon los bienes de Víctor Silvero, en su establecimiento rural situado en el Departamento Santo Tomé, procediéndose al arreo de sus animales para provista de las tropas aliadas (ver: AGPC, CNMG, Libro notas a jueces de paz, 1864-1869. F.209). Respecto al establecimiento rural afectado, varios años después de la guerra, se planteó un litigio en la Justicia federal (ver escritos presentados por el "Fisco ante la Excma. Cámara Federal de Paraná. Juicio de Reivindicación del campo denominado "San Mateo", seguido por Don Antonio I. Ruiz contra Don Victor Silvero - hoy Alfredo Fornus". Corrientes, Imprenta del Estado, 1928. 
alimentarias para sobrevivir. ${ }^{87}$ La situación se revirtió cuando en 1866 el gobernador Evaristo López dejó sin efecto la orden de Lagraña, por considerar que fueron dispuestas ilegalmente, sin juicio previo, ni ejecutadas por autoridad competente. ${ }^{88}$

Pero las necesidades de guerra de los Aliados también llevó obligatoriamente a tomar medidas que impactaron directamente sobre los ya perjudicados correntinos, exigiendo incautar, en 1866, todo ganado equino, entregándoseles vales con promesa de pago. Esto exigió al extremo a los habitantes de la provincia y, al decir de Thomas Whigham, algunos propietarios vieron sus hogares destrozados, primero por los paraguayos, luego por los correntinos y, finalmente, por desertores de ambos bandos. ${ }^{89}$

Luego de las traumáticas consecuencias por los saqueos al poblado de Bella Vista, el Gobierno provincial inició la reconstrucción política a través de la autoridad local del Juez de paz, y muestra de aquella normalización fueron las elecciones municipales realizadas a menos de un año del retiro del ejército paraguayo. ${ }^{90} \mathrm{La}$ práctica de aquellas elecciones fueron muestras que la construcción estadual estaba en marcha nuevamente, incursionando en una práctica constitucional que la vida política correntina siempre quiso imponer, a pesar de sus revoluciones, sediciones y rebeldías.

\section{Conclusiones}

Los meses que duró la ocupación efectiva del territorio correntino por las fuerzas paraguayas lo transformaron en un campo de batalla sin límites ni discreción. Los distintos enfrentamientos con los batallones argentinos de vanguardia hicieron del territorio provincial un único y constante campo de batalla, con la consecuencia de destrucción que ello implica.

El avance de las columnas que bordearon la costa del río Paraná generó múltiples destrozos en la propiedad privada y pública, incluyendo el comercio y la producción rural. Departamentos como Empedrado, San Roque, Saladas, Bella Vista, Yaguareté Corá (Concepción), entre otros, son muestra de la violencia desatada.

Específicamente, en el caso de Bella Vista, la cuestión alcanzó extremos de un ensañamiento destructivo, siendo una de las mayores expresiones de violencia registrada contra un poblado correntino en aquella guerra. Después del departamento San Luis del Palmar, el de Bella Vista -con 316 expedientes-, es el que presentó la mayor cantidad de reclamos ante el Ministerio de Relaciones Exteriores de la Nación en el año 1877, lo que muestra la magnitud de los daños.

El ataque desmedido a Bella Vista fue la muestra de impotencia de la política paraguaya, al complicarse militarmente en territorio correntino. El asalto despiadado y sin límites se da en gran medida por la imposibilidad paraguaya de alcanzar los logros

\footnotetext{
${ }^{87}$ AGPC, Expedientes Administrativos, Legajo 145, Enero-Diciembre 1866.

${ }^{88}$ ROPC, Años 1865-1866, Imprenta de "La Verdad", Corrientes, 1877, p 138.

${ }^{89}$ Whigham, Thomas, 2010. La guerra de la Triple Alianza. Causa e inicios del mayor conflicto bélico de America del Sur, Volumen I, Asunción, Ed. Taurus, p. 431.

${ }^{90}$ AGPC, Correspondencia Oficial, Tomo 218, Fs. 5 y 6.
} 
Ramírez Braschi. Bella Vista durante la ocupación paraguaya (1865).

propuestos, que incluía la hipótesis máxima de generar una alianza con Urquiza, ${ }^{91} \mathrm{o}$ hacer que éste colaborase con los paraguayistas.

Además, no se cubrieron las expectativas de adhesión masiva de la población correntina. Nada de esto ocurrió. La alianza con los correntinos paraguayistas no fue suficiente, y sólo predominó la desorganización e incertidumbre. Orgánicamente lograron armar algunos batallones de correntinos que, con la bandera de la provincia, combatieron junto a los paraguayos. El revés naval en Riachuelo (11 de junio de 1865), y las adversidades en las operaciones terrestres, terminaron por diluir toda posibilidad de triunfo paraguayo en territorio correntino.

La impotencia paraguaya llevó a cometer ataques desmedidos a la población, lo que produjo una brecha profunda y un rechazo definitivo hacia las tropas invasoras. Si bien existió alguna posibilidad de entendimiento o seducción hacia la población correntina, los actos posteriores terminaron por generar un efecto totalmente adverso.

\section{Referencias bibliografícas}

Archivo del General Mitre. Biblioteca La Nación. Buenos Aires. 1911.

Beverina, Juan. 1921. La guerra del Paraguay, Tomos I al V. Buenos Aires.

Braga, Alfredo. 1911. As Apolices Paraguayas e Os Portadores Brazileiros, Rio de Janeiro. Typographia Leuzinger.

Brezzo, Liliana M.- Figallo, Beatriz. 1999. La Argentina y el Paraguay, de la guerra a la integración. Rosario, Instituto de Historia. Facultad de Derecho y Ciencias Sociales del Rosario, Pontificia Universidad Católica Argentina.

Brezzo, Liliana. 2004, "La guerra de la Triple Alianza en los límites de la ortodoxia: mitos y tabúes". En: Revista Universum, Nro. 19 - Vol. 1:10-27.

Burton, Richard F. 1998. Cartas desde los campos de batalla del Paraguay, Buenos Aires, Librería El Foro.

Capdevila, Luc. 2010. Una guerra total: Paraguay, 1864-1870. Ensayo de historia del tiempo presente. Trad. de Ana Couchonnal. Asunción. Ed. Sb. Centro de Estudios Antropológicos de la Universidad Católica, Buenos Aires.

Cárcano, Ramón. 1941. La guerra del Paraguay, Buenos Aires, Ediciones Domingio Viau y Cia.

Centurión, Juan Crisóstomo. 1976, Memorias o Reminiscencias Históricas sobre la guerra del Paraguay, Tomo I. Asunción, Editorial Casa Libro.

Doratioto, Francisco. 2004. Maldita Guerra. Nueva historia de la guerra del Paraguay, Buenos Aires, Ed. Emecé.

Exposición que hace a los miembros del Congreso el ciudadano Telésforo A. Díaz, en su reclamación al Gobierno argentino por la pérdida de dos cargamentos de artículos destinados al ejército correntino, al inicio de la guerra del Paraguay, en el año 1865. 1878. Buenos Aires. Imprenta de Pablo E. Coni.

García Mellid, Atilio. 1964. Proceso a los falsificadores de la guerra del Paraguay, Tomos I y II, Buenos Aires, Ediciones Theoría.

${ }^{91}$ Centurión, Juan Crisóstomo, 1976. Memorias o reminiscencias históricas sobre la guerra del Paraguay, Tomo I, Reedición, Asunción, Editorial Casa-Libro, p. 238 - Doratioto, Francisco. 2004. Maldita Guerra. Nueva historia de la guerra del Paraguay, Buenos Aires, Ed. Emecé, p. 128. 
Mantilla, Manuel Florencio. 1972. Crónica Histórica de la provincia de Corrientes. Tomo II. Buenos Aires.

Nabuco, Joaquín. 1901. La Guerra del Paraguay. Versión castellana de Gonzalo Rejaraz, París, Ed. Garnier Hermanos.

Pomer, León. 1986. Cinco años de guerra civil en la Argentina 1865-1870. Bs. As. Amorrortu Editores.

Ramírez Braschi, Dardo. 2001-2002. "El gobierno de Manuel I. Lagraña durante la ocupación paraguaya a Corrientes en 1865". En: Folia Histórica del Nordeste Nro. 15. Resistencia, Instituto de Investigaciones de Geohistóricas - CONICET, Instituto de Historia-(UNNE).

Ramírez Braschi, Dardo. 2004. La guerra de la Triple Alianza a través de los periódicos correntinos (1865-1870). Corrientes. Moglia Ediciones.

Rebaudi, Arturo. 1917, Guerra del Paraguay, Buenos Aires, Imprenta Constancia.

Rebaudi, Arturo. 1924. La declaración de guerra de la República del Paraguay a la República Argentina. Buenos Aires, Ed. Serantes Hnos. Impresores.

Resquín, Francisco I. 1996. La guerra del Paraguay contra la Triple Alianza, Asunción, Ed. El Lector.

Rosa, José María. 1985. La guerra del Paraguay y las montoneras argentinas. Buenos Aires. Peña Lillo Editor.

Ruiz Moreno, Isidoro J. 2008. Campañas militares argentinas. La politica y la guerra. Guerra exterior y luchas internas (1865-1874), Tomo IV, Buenos Aires. Ed. Claridad.

Thompson, Jorge. 1901. La guerra del Paraguay. Tomos I y II. Buenos Aires. Talleres Gráficos de L. J. Rosso y Cia.

Whigham, Thomas. 2011. La guerra de la Triple Alianza. Volumen I y II. Asunción, Ed. Taurus. Zjarks, Germán O. E. 1977. "Nueva luz sobre el origen de la Triple Alianza". En: Revista Historia. Número 1. Buenos Aires. 